\title{
黔北志留纪早期枝线贝类介壳层的时空分布和 风暴沉积特征
}

\author{
李 越( 戎嘉余 ${ }^{\circ}$ \\ (1) 中国科学院南京地质古生物研究所, 南京 210008; (2) 古生物学和地层学国家重点实验室, 中国科学院南京地质古生物研究所, \\ 南京 210008. E-mail: yueli@nigpas.ac.cn)
}

\begin{abstract}
摘要 上扬子区下志留统灰岩中发育良好的与海洋风暴事件相关的腕足动物枝线贝类介壳层. 它见于 黔北香树园组近顶部或石牛栏组上部, 由 2 个县花一现的浅海土著分子拟壳房贝属 (Paraconchidium) 或小枝线贝属(Virgianella)以不同比例混合、非原始正常栖居方式的碎壳与灰泥共同堆积而成. 单层厚 度少则仅数十厘米, 多则达 $4 \mathrm{~m}$ 多. 其中的壳体皆遭遇过高能水流强烈搅动, 特别是较薄的腹壳前部和 背壳, 更是破损严重, 其形成的主要动力是风暴和海岸线形状共同导致的增水作用; 据相关群落的生态 位(BA2 下部至BA3 上部)推测, 它们是近岸浅海风暴作用的产物, 介壳的破碎及其堆积的疏密程度反映 了近源和远源风暴成因. 志留纪时处于南低纬度的黔北海域, 在广海强水团到达时, 加剧的能量强烈地 波及到枝线贝类群落栖居的深度. 多数介壳滩被风暴反复冲淘, 推测其堆积时间可达数万年.
\end{abstract}

\section{关键词 贵州北部 兰多维列统 香树园组 石牛栏组 枝线贝类 腕足类 风暴介壳层}

本文研究贵州北部志留纪中兰多维列统埃隆阶 以五房贝族枝线贝类为单一或绝对优势种的贝壳堆 积层, 阐述其特征和时空分布, 旨在证实这是发生在 4 亿多年前华南板块近岸浅海台地上风暴作用的产 物.

“风暴”是指台风或龙卷风等所造成的大风、暴雨 的恶劣天气, 其中风力达到蒲氏 12 级的热带气旋称 为“飓风”. 大气环流、天文大潮甚至海底地震单独或 共同作用形成的海啸, 可使海水位迅速暴涨并向陆 地快速侵溢, 强烈地改造着一定深度的海底生物和 沉积物. 现代某些沿岸地带的海洋“风暴潮”, 发生频 率为数次/年, 最大强度甚至可波及到水深约 $200 \mathrm{~m}$ 处的海底. Ager ${ }^{[1]}$ 提出风暴层一词来定义在风暴潮作 用下形成的特殊沉积组合; Aigner ${ }^{[2]}$ 首次建立风暴沉 积系统模式; Barron ${ }^{[3]}$ 分析了地史时期的风暴记录. 这些成果使我们对史前风暴沉积始有基本了解.

直于地层记录不完整性(如缺乏记录风暴信息的 载体)和古地理知识局限性(风暴层多形成于低纬度 俱风区), 识别史前地层记录中的“风暴事件”, 远远 达不到以年为单位的精度. 短暂风暴形成的堆积物, 极有可能被下次风暴带走并运移到别处堆积. 从这
个意义上说, 快速堆积和被破坏的两种概率几乎持 平, 即所谓“大浪淘沙, 周而复始”. 风暴层起因于短 暂事件、堆积在风暴波及的深度之上, 可作为一种 “标志层”, 用于区域地层的高精度对比.

志留系的风暴层, 无论在碳酸盐岩相还是硅质 碎屑岩相中, 皆有实例报道, 但多来自欧、美两洲, 如阿瓦隆尼亚( Avalonia)、劳伦(Laurentia)和波罗的海 (Baltica)等板块 ${ }^{[4]}$. 中国志留系的风暴沉积报道很少. 戎嘉余等人 [5]曾记述新疆准噶尔西缘Ludlow统的五 房贝类Pentamerifera堆积层, 推测当时海底发生过强 大的水动力灾变事件. 张廷山等人 [6]记述川陕边界 广元、宁强一带兰多维列统上部宁强组中的“风暴岩”, 认为强大水流淘洗掉了海底较细的泥质物, 较粗的 钙质生物骨骼(如棘屑等)更易集中堆积, 成为有利于 造礁生物群落生长的硬底. Baarli ${ }^{[4]}$ 指出, 华南板块虽 位于冈瓦那大陆的背风面, 在Llandovery末期宁强组 中仍有风暴层出现. 但是, 宁强组的风暴层与本文研 究的情况有很大的差异.

志留系的五房贝层常见于碳酸盐岩地层, 壳体 多保存完好, 但也时见风暴作用后的碎壳堆积层 [5]. 华南兰多维列统浅海相的多类五房贝层相当丰富, 
枝线贝类介壳层发育于黔北的香树园组近顶部或石 牛栏组上部(图 1), 分布在黔中古陆以北不远的陆表 海域(图 2)，时代为中埃隆期 [7]. 海区东西和南北延 伸的沉积相分异，主要受控于东侧的华夏古陆和南 缘的滇黔桂古陆. 东西向分异表现为东部的香树园
组灰岩夹泥岩相变成西部的龙马溪组上部碎屑岩和 石牛栏组灰岩; 南北向分异在于发育近岸、浅海台地 灰岩相的白沙型和远岸、较深水台地泥灰岩/泥岩交 互相的印江型 ${ }^{[8]}$. 白沙型的识别和研究始于 20 世纪 70 年代 ${ }^{[8,9]}$, 具下列 3 种标志: ( i ) 腕足类介壳滩;

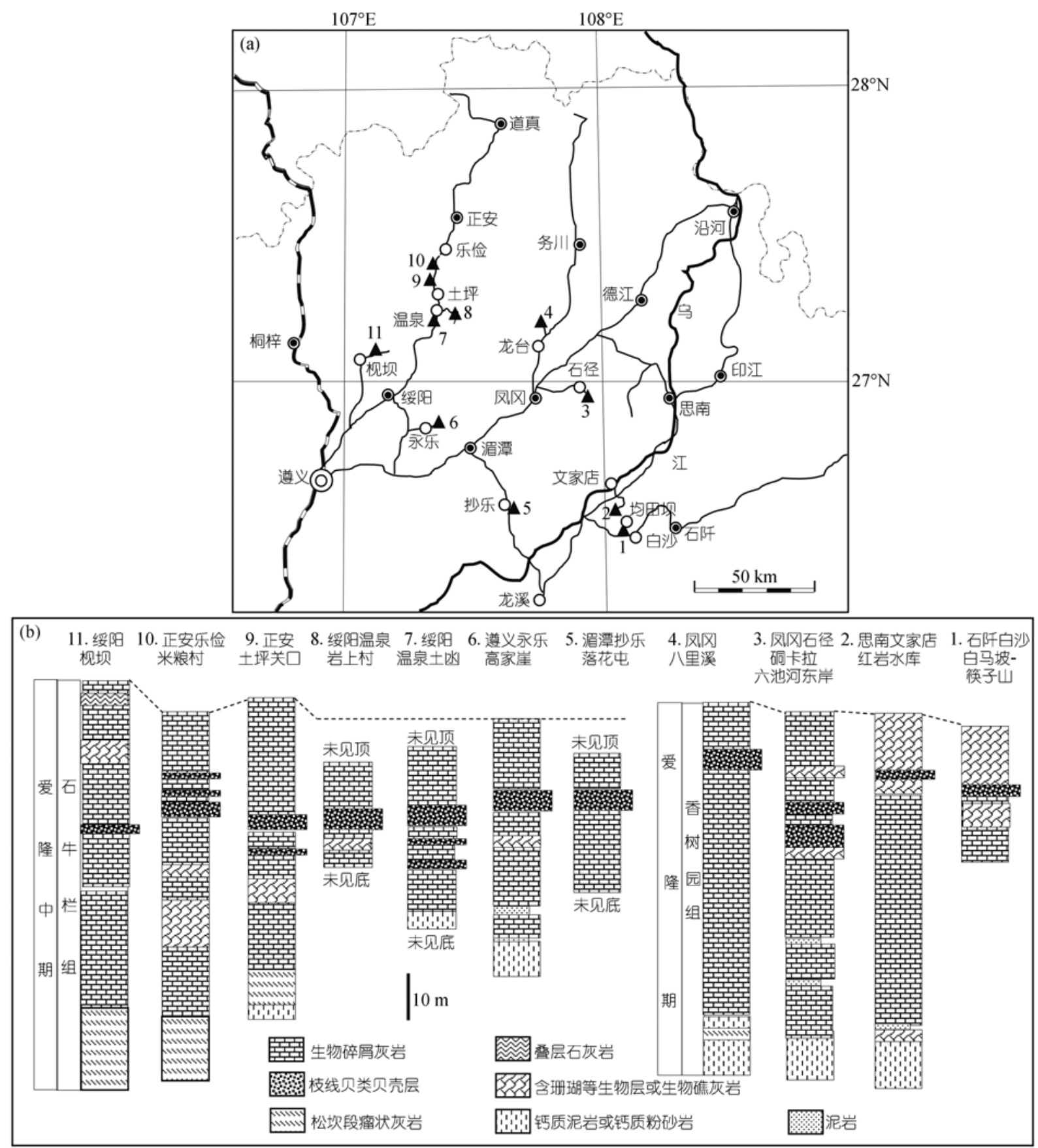

图 1 黔北地区下志留统枝线贝类介壳层的时空分布

(a) 剖面地理位置, 剖面号的地点见对应的剖面柱状图; (b) 剖面沉积序列, 部分很薄的枝线贝类层作了放大, 厚度记录见文字部分. 


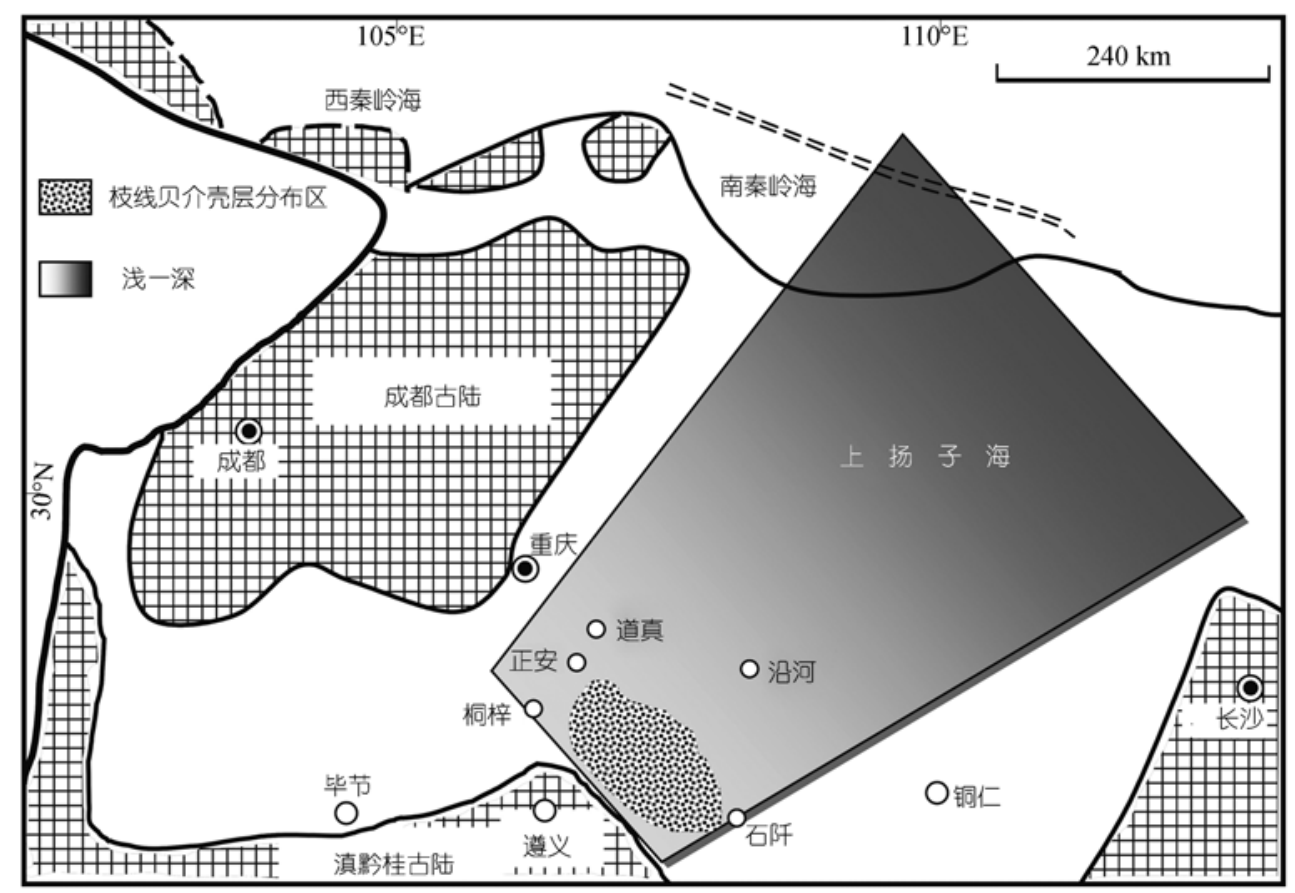

图 2 黔北地区志留纪早期中爱隆期的古地理图和枝线贝类介壳层产生的背景 灰色梯形表示风暴潮由外海向滇黔桂古陆侵漫过程中的增水过程

（ii ) 珊瑚-层孔虫点礁或生物层; (iii) 海百合棘屑滩 (由大量散落的海百合茎夹杂少量珊瑚碎块堆积而 成). 滩相腕足类介壳组合包括枝线贝类、五房贝类、 无洞贝类和三分贝类等, 以第一种最常见, 此即本文 聚焦的内容.

\section{1 时空分布}

贵州北部枝线贝类介壳层中, 富含五房贝超科枝 线贝科(Virgianidae)的石阶拟壳房贝(Paraconchidium shiqianensisi 戎嘉余等人 $)^{[9,10]}$ 或光滑小枝线贝 (Virgianella glabera 戎嘉余和杨学长) ${ }^{[9]}$, 它们或共生, 如石阶白沙白马坡和凤冈八里溪, 或分别产出, 如石 阶均田坝和正安土坪. 两者内部构造很相似, 如腹壳 支持匙形台的中隔板较长且厚实, 背壳外腕板相向 聚合, 差别在于V. glabera壳表光滑, P. shiqianensis发 育壳线, 但在切面标本上难以分辨.

大量枝线贝类的贝壳，常以个体大小不一、破碎 程度不同和埋葬密集程度有别为特征, 有时混入个 别珊瑚(如 Crystiphyllum, Favosites). 介壳灰岩中, 黑 (灰泥)白 (贝壳)分明(图 3(a) (d)), 泼水后尤为醒目. 在同一剖面上, 常可识别出 1 4 个厚薄不一的堆积序 列, 单层厚约 $0.1 \mathrm{~m}$ 至数米不等, 之间被其他类型的 灰岩层隔开.
枝线贝类介壳层的时代, 有必要作些说明. 黔东 北香树园组上部加雷家屯组大致相当于黔北石牛栏 组 ${ }^{[7]}$. 但两者间没有截然的相变界线, 横向上呈犬牙 交错状; 总体上说, 黔东北泥质成份多, 黔北灰质成 分占优. 由于无可靠的笔石和牙形类化石, 其时代难 以精确确定, 大致相当于埃隆中期(图 1) 而非原定的 特列奇期 ${ }^{[8]}$, 这是从上、下伏地层所含化石推测的. 由于其层位稳定、厚度不大, 可视为该区志留纪风暴 频繁发生期大致同时、可行对比的标志层.

葛治洲等人 ${ }^{[8]}$ (见文献 [8]178 页的图5)曾记述 9 个白沙型礁滩相地点: 石阶白沙和均田坝, 思南㸗溪, 凤冈硐卡拉和八里溪, 湄潭兴隆场和松烟, 绥阳温泉 以及正安土坪. 戎嘉余等人 ${ }^{[10]}$ 又补充了石阶白沙水 田沟、凤冈绥阳场和正安城北黄家屋基 3 处. 本文作 者重新厘定它们在黔北的分布, 排除了不盛产枝线贝 类介壳层的点, 增加了若干新产地(图 1(a)), 并制成其 沉积序列图(图 1(b)). 现按东西、南北向分述如下:

(i ) 石阶白沙地区(4 个产地). 20 世纪 70 年代初, 戎嘉余等在白沙镇北均田坝、镇附近的白马坡和水田 沟的香树园组上部, 首先寻获枝线贝类介壳层, 分别 厚 3.7, 2.43, $4.1 \mathrm{~m} .1998$ 年秋, 李越 111$]$ 在白马坡向东 $300 \mathrm{~m}$ 筷子山寻获该介壳层(厚 $2.5 \mathrm{~m}$ ). 上述地点相距 

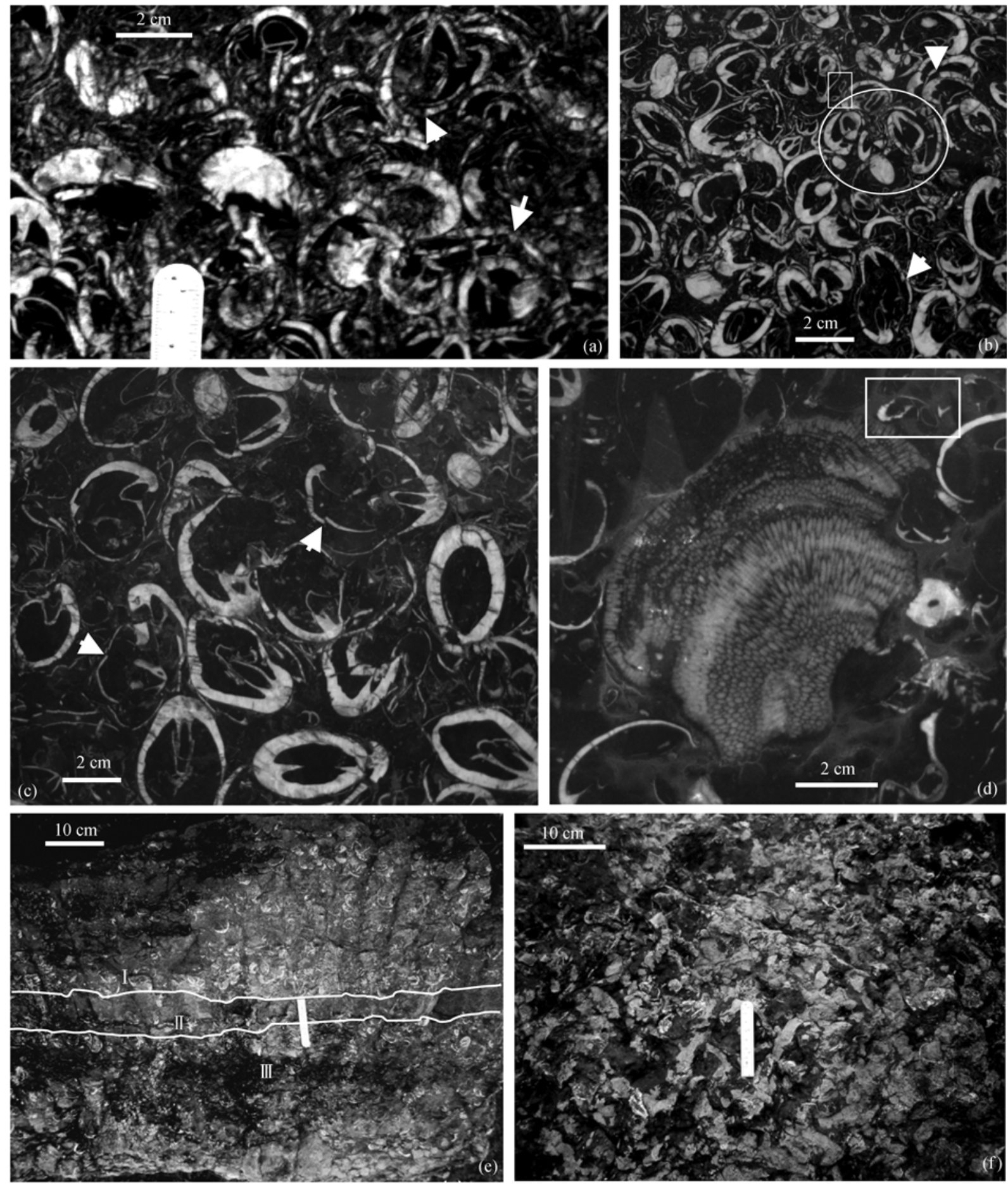

图 3 遵义永乐高家崖枝线贝类介壳层的两种岩性特征

(a) (d)摄自平行层面磨制的抛光面, (a) (c) 灰泥颗粒岩, (d) 颗粒灰泥岩. (a) 壳体强烈破碎、紧密堆积, 在成岩过程中较坚厚的腹壳也被挤压折 断(箭头指示折断部位, 下同); (b) 密集的壳体破碎程度中等, 腹壳大部分被保存, 较大的被较小的碎壳片套叠(圆圈所示), 少量较薄的背壳也偶 然保存(白框所示); (c) 灰泥颗粒岩中较完整的壳体; (d) 保存较完好的块状蜂巢珊瑚与破碎程度较低的腹壳(含白框内的背壳); (e) 两种沉积在 露头纵向上交互产出： I , III：灰泥颗粒岩, 贝壳密集; II：颗粒灰泥岩, 贝壳稀疏; (f) 颗粒灰泥岩中的遗迹化石 Thalassinoides 
仅数公里, 介壳层上、下沉积序列相似, 唯厚度有变. 其基底是含核形石、层孔虫和珊瑚的生物层灰岩, 上 覆地层为含块状复体珊瑚的生物层灰岩 [11].

(ii ) 思南文家店. 据贵州省区域地质调查大队 记载, 红岩水库附近的香树园组上部发育枝线贝类 介壳层, 厚 $4.15 \mathrm{~m}$, 较密集的层厚 $0.7 \mathrm{~m}$, 中间夹四射 珊瑚生物层灰岩, 下伏地层为泥质条带状生物碎屑 灰岩, 上覆地层为含沥青质的生物礁或生物层灰岩.

(iii) 凤冈石径硐卡拉(至少含 2 个产地). 石径乡 以西约 $3 \mathrm{~km}$, 硐卡拉水电站至青滩大桥公路西侧和 与公路平行的六池河东岸, 均发育石牛栏组. 1998 年 春, 戎嘉余等实测公路西侧枝线贝类介壳层, 共识别 上、下两层(间隔 $6.5 \mathrm{~m}$ ): 下层 $4.21 \mathrm{~m}$, 上层 0.34 和 $0.10 \mathrm{~m}$; 再往上约 $10 \mathrm{~m}$ 处, 出现 Trimerella 介壳层 $(0.36 \mathrm{~m})$; 向上约 $25 \mathrm{~m}$ 为石牛栏组顶界的不整合面. 2005 年春, 李越实测河东岸距前一地点约 $150 \mathrm{~m}$ 的 剖面, 发现枝线贝类介壳层: 下层厚度减至 $3 \mathrm{~m}$, 有 10 个介壳疏-密相间的堆积旋回; 上层增厚至 $1.8 \mathrm{~m}$, 发育 4 个疏-密相间堆积旋回, 且有少量海百合茎灰 岩角砾混杂(图 4(e)). 上、下介壳层间发育 $2 \mathrm{~m}$ 厚的 浅灰色鸟眼构造泥晶灰岩(图 4(d)). 其基底为中薄层 含大量珊瑚的瘤状生物层灰岩(图 4(f)).

(iv) 凤冈八里溪. 据葛治洲等人 ${ }^{[12]}$ 记载, 自龙台 八里溪开始, 沿绥阳场-土溪公路发育志留纪地层, 香 树园组上部距顶 $14 \mathrm{~m}$ 处为厚 $4.2 \mathrm{~m}$ 的 $P$. shiqianensis介 壳层, 共生的有头足类Songkanoceras. 下伏地层为灰 色薄层瘤状泥晶灰岩生物层, 含丰富珊瑚和腕足类, 夹少量灰黄色泥岩, 偶夹灰岩透镜体; 上覆地层为灰 色瘤状泥晶灰岩, 含腕足类Eospirifer.

( v ) 湄潭兴隆场抄乐. 石牛栏组出露于抄乐乡 以南约 $1.5 \mathrm{~km}$ 的落花屯附近一个废弃的小型采石场 内. 地层剖面产状几近直立. 尽管覆盖严重, 但介壳 层的顶、底层位尚能控制. 该介壳层厚 $3.6 \mathrm{~m}$, 介壳层 之上为含格架状珊瑚和受食迹的薄层泥晶灰岩.

(vi) 遵义永乐. 1998 年春, 戎嘉余等在遵义团泽 乡石料加工厂观察到采自遵义城东北永乐镇西北约 4 $\mathrm{km}$ 高家崖的枝线贝类介壳层石材. 2005 年秋, 李越 赴该剖面实测该介壳层厚 $3.7 \mathrm{~m}$, 由 5 6 个疏-密相间 的堆积旋回组成. 不论在贝壳密集或是稀疏的层中, 皆杂含少量块状蜂巢珊瑚(Favosites), 而原地生长的 大型格架状四射珊瑚和遗迹化石多出现于贝壳稀疏 层中. 介壳层上、下皆与薄层泥晶生物灰岩整合接触. (vii) 绥阳温泉土咏. 温泉镇南北是一直立背斜 的南北两翼. 镇南在 207 省道 $152 \mathrm{~km}$ 路碑处, 在石牛 栏组上部发育 3 层枝线贝类介壳层, 从下到上厚度依 次为: $0.53,0.67$ 和 $1.36 \mathrm{~m}$. 其间, 由下至上, 分别隔 有 $0.7 \mathrm{~m}$ 珊瑚格架岩和 $0.13 \mathrm{~m}$ 含零星枝线贝的生物碎 屑灰岩. 这样, 介壳层总厚为 $3.39 \mathrm{~m}$. 上下灰岩中含 少量海百合茎和珊瑚碎屑.

(viii) 绥阳温泉岩上村. 温泉镇北(即背斜北翼)剖 面, 与土咏剖面相距约 $4 \mathrm{~km}$, 沿 207 省道 $150 \mathrm{~km}$ 路 碑东侧土石公路走到尽头即是. 产状几近直立, 介壳 层厚 $2.4 \mathrm{~m}$, 有些层中几乎所有壳体均遭强烈破碎, 密集重叠(图 4(c)). 下伏地层为厚层含珊瑚一层孔虫 等生物碎屑灰岩, 上覆地层是海百合茎为主的中薄 层瘤状生物碎屑灰岩.

(ix) 正安土坪. 土坪镇北 $3.5 \mathrm{~km}$ (即 207 省道 137 138 km 间)处的关口, 地层产状几近直立. 石牛 栏组上部介壳层中的化石多呈密集式堆积. 从下至 上, 发育两层 0.17 和 $1.3 \mathrm{~m}$ 厚的介壳层, 之间被 $0.4 \mathrm{~m}$ 厚的生物碎屑灰岩夹页岩分开. 顺层向北延伸约 150 $\mathrm{m}$ 处, 厚度略有变化, 分别为 0.12 和 $1.53 \mathrm{~m}$. 介壳层 之下为薄层泥质条带灰岩, 局部发育灰岩角砾构成 介壳层基底(图 4(b)); 上覆地层为薄层泥晶灰岩, 具 多角状龟裂纹构造.

(x) 正安乐俭米粮村. 石牛栏组上部介壳层出 露于 207 省道 $127 \mathrm{~km}$ 路碑处西侧陡坡上. 3 层介壳层 从下至上分别为 $1.9,0.22$ 和 $0.13 \mathrm{~m}$ 厚, 层间分别被 0.6 和 $0.29 \mathrm{~m}$ 的深灰色泥晶灰岩所间隔. 介壳化石破 碎程度中等、多以密集方式保存. 上、下地层均为中 薄层含少量块状珊瑚的深灰色或灰色泥晶灰岩.

( $x i$ ) 绥阳枧坝. 石牛栏组上部的枝线贝类介壳 层出露于枧坝镇以北约 $5 \mathrm{~km}$ 的土石公路旁陡崖边, 仅发育 1 层, 在数米延伸距离内厚度从 $0.13 \sim 0.2 \mathrm{~m}$ 发 生变化; 介壳化石以中等破碎度和密度方式堆积. 下 伏地层为深灰色薄层瘤状泥晶灰岩; 上覆地层为灰 色薄、中层生物碎屑灰岩, 含少量小型块状珊瑚.

上述 15 个地点的资料表明，黔北枝线贝类介壳 层厚度多在 3 4 m 间, 凤冈石径乡六池河东岸的介壳 层累计厚度为 $4.8 \mathrm{~m}$, 是已知厚度最大之处; 石阶白 沙一带为介壳层分布的最东南端; 绥阳枧坝则是其 展布区的最西端, 也是最薄的点; 正安乐俭是该层分 布的最北点; 推测枝线贝类介壳层南缘可能大致与 黔中古陆北缘平行, 0 相距不远. 据此, 估算出枝线贝 

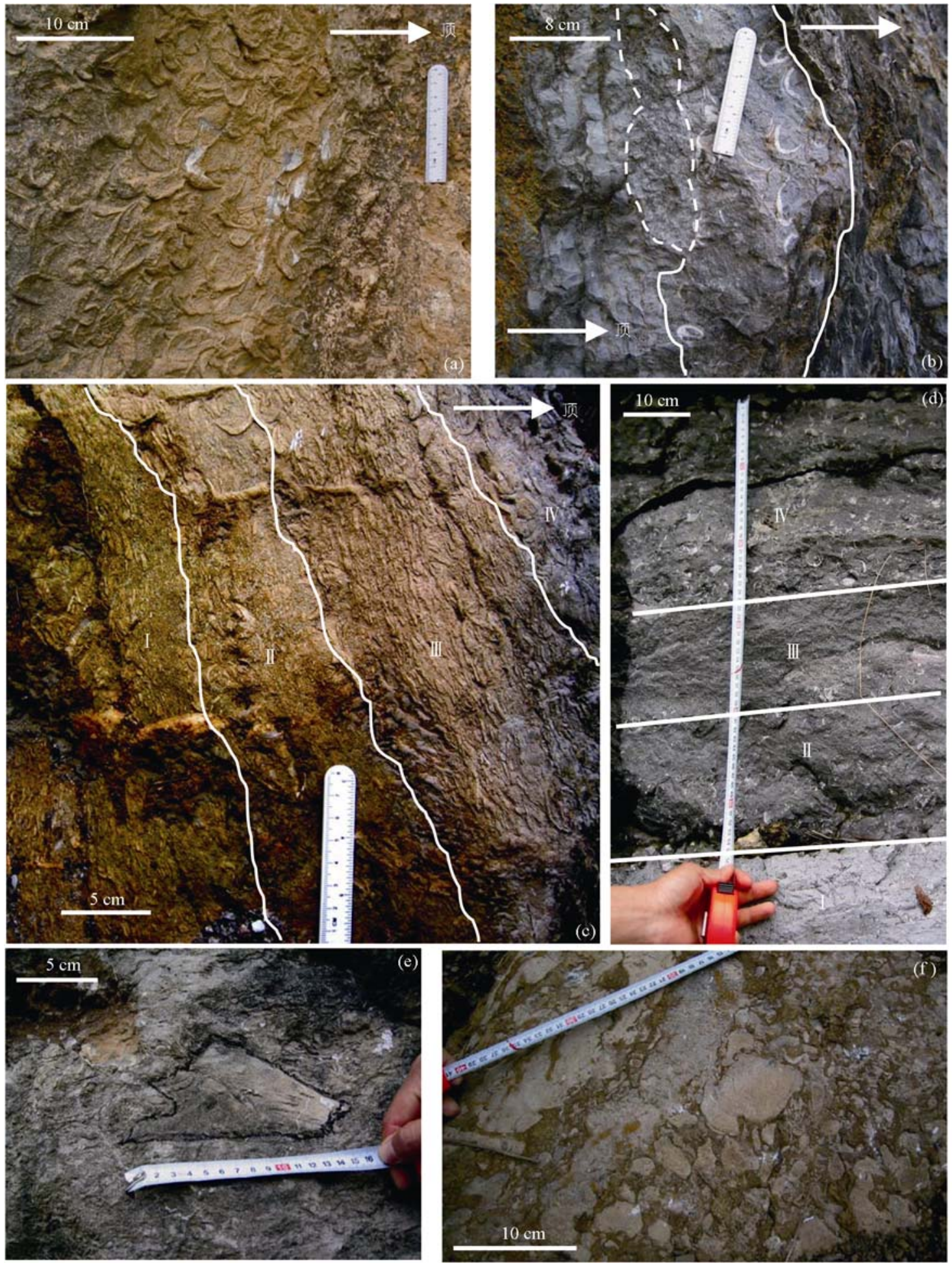

图 4 介壳层的沉积序列

(a) 贝壳堆积时, 腹壳多凸面向下(正安土坪关口); (b) 介壳层基底被冲蚀, 白色虚线内的凹槽中发育灰岩角砾堆积, 之上才见贝壳堆积(正安土 坪关口); (c) 在连续的灰泥颗粒岩介壳层沉积序列中, 壳体破损程度存在明显差异: I, III 为贝壳强烈破损; II, IV 为贝壳中等程度破损(绥阳温 泉岩上村); (d) 在连续的颗粒灰泥岩介壳层沉积序列中, 壳体密度和破损程度在纵向上存在明显差异: I 上介壳层基底为具鸟眼结构的灰岩, II, IV 为中等密度堆积和中等程度破碎, III 为介壳破碎成毫米级, 零星散落(凤冈石径硐卡拉); (e) 介壳层中混杂大型含海百合茎灰岩的角砾(凤 冈石径硐卡拉);(f) 介壳层之上的珊瑚生物层灰岩(凤冈石径硐卡拉) 
类介壳层展布范围位于上扬子海域南部浅海碳酸盐 岩台地内, 约有 $7500 \mathrm{~km}^{2}$.

\section{2 岩石特征与水动能指标}

在已知的枝线贝类标本中, 除极个别腹、背两壳 完整铰合的标本 ${ }^{[9,10,13]}$ 外, 其余都是破损程度不同、两 壳分离的. 遵义永乐高家崖石牛栏组上部的石材板, 清晰地显示了贝壳堆积的不同方式. 据Dunham ${ }^{[14]}$ 提 出的碳酸盐岩沉积结构分类方案, 枝线贝介壳层可 分成两类: (i ) 由颗粒支撑、灰泥充填的灰泥颗粒岩, (ii ) 由灰泥支撑、颗粒充填的颗粒灰泥岩. 黔北志留 系灰岩成份中, 大多以灰泥占优势, 其成因大多是直 接沉积的, 也可能是菌藻类成因的文石针泥晶化, 或 是壳相生物长时间以各种方式降解的结果; 部分灰 泥成分似为粪球粒, 可能系由蠕虫的活动所致; 灰岩 局部因层间压溶而在灰泥孔隙内发生重结晶的现象. 总之, 灰泥的生产量大, 无处不在, 它在介壳层中的 含量是环境分析的重要指标. 两种灰泥含量不同的 介壳层类型在同一剖面上可单一(图 4(c), (d))或交替 (图 3(e)) 出现, 指示了介壳堆积时水动力强度的差异.

\section{1 灰泥颗粒岩}

本类型的颗粒是由大小不等的贝壳碎片密集组 成. 腹壳中后部壳壁及其相关构造(如匙形台)因厚度 较大, 多能保存; 壳前部薄脆, 易于断裂破碎; 背壳 中前部壳壁也薄, 破碎程度更高, 能保留背壳后部腕 房构造的残片极少(图 3(b), (d)). 大量碎壳杂乱无章 地在腹腔内充填, 有时贝壳套叠而紧密堆积(图 3(b)). 即使同为壳体支撑的灰泥颗粒岩，壳体破损度也大 有差异(图 3(a) (c)). 正安温泉岩上村的介壳层中, 强 烈破损的贝壳只留下腹壳最厚部分的残片，且边缘 多被磨圆(图 4(c)), 这是在黔北所见最大程度破损的 实例, 指示最大的水动能指标.

大量薄的壳壁在最后堆积前均已处在悬浮状态、 被高能水流直接冲击, 壳瓣或因相互撞击、或因风浪 冲击而破碎; 但部分壳体的断裂很可能是在最后沉 降海底后, 被巨浪强击海底的压力折断的; 或在成岩 过程中受剪切应力作用而发生错位(图 3(b), (c)), 但 这种破碎方式在比例上要低.

\section{2 颗粒灰泥岩}

此类型的贝壳密度较疏, 多出现在灰泥或粉砂 屑级的基质中. 多数壳体的破碎程度相对较低, 个别 块状蜂巢珊瑚(Favosites)在灰泥基底上以原位固着生
长状态保存(图 3(d)). 虽然块状珊瑚比枝线贝类更能 抗浪, 但高含量的灰泥成分和大多数情况下低破碎 度的贝壳, 均指示当地水动能的影响力有所减弱.

但是, 壳体的堆积密度与破碎程度并不存在线 性相关. 尤其是一些较特殊的颗粒灰泥岩, 颗粒是由 零星的、破碎成毫米级的贝壳砂砾所组成(图4(d)). 灰 泥颗粒岩所指示的水动能量显然比颗粒灰泥岩的高. 在灰泥堆积期, 水动能明显偏弱, 有利于遗迹化石如 海生迹(Thalassinoides)的形成(图 3(f)).

上述两种岩石类型存在着过渡关系, 指示水动 能高低的渐变性. 此外, 介壳层壳体密集程度在纵向 上虽有旋回性, 层理却不明显, 壳体几乎均匀地散布 在同一疏层或密层的各个部位.

\section{3 成因解释}

奥陶纪末冈瓦那大陆冰川造成全球海面下降 [15]. 志留纪初全球气候回暖, 海面上升 ${ }^{[16 ~ 18]}$. 黔北香树 园组或石牛栏组沉积序列指示了爱隆期区域性海退 过程 [7]. 当时华南大致位于南半球低纬区 $\left(15^{\circ} \sim 30^{\circ}\right)^{[18]}$, 黔北位于扬子区偏南, 大致在南纬 $20^{\circ}$ 左右, 与现代海洋俱风多发区(集中在 $20^{\circ} \sim 30^{\circ}$ ) 的纬 度一致. 大量喜暖的菌藻类、珊瑚和层孔虫繁盛的生 物礁和生物层建造, 从另一侧面证实当时本区属于 温暖浅海的推断 $[19,20]$.

志留纪早期扬子陆表海海域在东西和南北向延 伸了上千公里 ${ }^{[7]}$, 三面环陆: “成都古陆”(西侧)、“滇 黔桂古陆”(南侧)和华夏古陆(东侧)(图 2). 这种古地 理态势使北方广海上涌来的水团厚度加剧, 即增水 作用, 强烈地波及到P. shiqianensis或V. glabera群落 原始栖息深度. 其分布区西南缘离当时黔中古陆北 岸仅约 $20 \mathrm{~km}$, 似佐证了风暴和海岸线具体形状共同 导致的增水作用. 当风暴掠过海面时, 强力驱动海水 以波浪形式前涌而形成风暴浪并对浅海堆积物进行 深刻改造, 搬运质点作圆周运动 [21]. 风暴潮所具有 “密度流”(density current)和“牵引流”(draft current)两 重性, 分别使海底沉积物作垂直和横向运动. 根据黔 中古陆以北海底地貌向北平缓倾斜 [22]、无陡斜坡等 背景因素, 该介壳层指示的风暴流应该以“密度流” 为主. 从石阶白沙附近的几个近距离贝壳风暴层的 分布点推测, 在数十平方公里的范围内, 贝壳呈广布 的滩式堆积, 并非以狭长的堤式展布.

枝线贝类个体大, 肉茎缺失, 以腹壳喙部朝下、 顶区陷入灰泥底为正常栖居方式. 原始埋葬群落以 
这种聚集特点保存. 但在黔北, 笔者从未发现过这样 保存的化石, 贝壳埋葬类型应属于Seilacher ${ }^{[23]}$ 划分的 “贝壳质风暴层”, 是“户积群”的一种类型. 风暴潮的 高能水流彻底重塑了这些个体正常死亡后的原始埋 葬状态: 巨浪波及时, 无数壳体被强烈掀起后遭遇冲 击且相互碰撞, 活着的贝体突遭死亡, 已死亡个体的 空壳被不断地箕扬且碎裂. 在局部地点, 如正安土坪 关口的介壳层基底, 还发现已成岩的基底被剥蚀现 象, 即瘤灰岩角砾(图 4(b)); 又如凤冈石径硐卡拉介 壳层中掺杂的角砾(图 4(e)); 均证实大强度的风暴, 甚至将已固结成岩的海底灰岩击碎. 再如绥阳温泉 岩上村, 残余腹壳的坚厚部位的边缘甚至被磨圆了 (图 4(c)). 风暴作用还会淘洗掉部分灰泥, 当能量减 弱时, 厚重和破碎的壳体重新堆积在海底. 这个粒度 分选过程使残余的介壳比例骤然增高, 形成介壳密 集的灰泥颗粒岩.

黔北介壳层中壳体叠置方式以腹壳凸面向下者 占优势(图 4(a)), 如正安土坪关口. 这与英格兰西南 部石炭系灰岩风暴层 ${ }^{[24]}$ 不一致, 后者的贝壳在风暴 作用下、从悬浮状态作最后沉降时, 起初凸面也多朝 下, 后经海底水流反复扰动、最终形成凸面向上, 形 成最大稳定方式的叠瓦状构造. 黔北材料凸面向下 的保存优势, 指示了风暴后沉降到海底的贝壳基本 上未受到后期能量较低的海底水流改造, 但不排除 多次风暴潮的反复作用. 这说明枝线贝类介壳层的 埋葬深度应在风暴潮波及的范围, 故比一般潮汐水 流作用的深度更深. 瞬间而多次的风暴并不能造成 灰泥被彻底淘净的后果(成岩后为亮晶胶结的灰岩), 既然部分灰泥能残存下来，厚重的枝线贝类壳体就 更不可能作长距离的运移了. 因此, 大部分壳体更可 能是在最大浪基面附近堆积的, 指示了风暴作用的 中心地带, 是一种近源风暴岩. 更有甚者, 壳壁上全 然未见藻类附生, 也未见粘结灰泥的泥晶套, 说明风 暴曾多次发生且持续不断, 使那些菌藻类没有机会 在风暴间隙期长成. 数米厚的介壳层的形成需要数 千年, 数厘米厚的介壳层的形成也要数百年, 因此, 它们是多次而非一次风暴事件的产物.

强水流淘洗的大部分灰泥及部分介壳碎片可能 在偏离风暴中心或在风暴潮减弱时才得以沉降; 且 非风暴期有利于沉降灰泥, 低能水流也能带来灰泥. 黔北香树园组上部出现与海岸线近于平行的生物礁 建造, 虽说这些礁与这些风暴层是否等时还不明, 0 但
不排斥生物礁的抗浪性能有效消减风暴的能量, 以 利于灰泥大量沉积, 形成颗粒灰泥岩. 因此, 此类介 壳层更类似于一种远源风暴岩. 凤冈石径硐卡拉的 颗粒灰泥岩有点特别(图 4(d)), 因未发现伴生有典型 的交错层理等潮坪环境标志性构造, 不大可能是潮 汐作用所致. 这些高破碎度和低密度的介壳屑可能 是风暴潮退水时将较轻的贝壳砂屑向更深水区携带, 并掺杂在灰泥中卸载沉降下来的. 可见, 这是一种更 特征的远源风暴产物.

需要强调的是黔北古生代地层多被后期构造挤 压变形, 现今介壳层分布的规模可能明显小于当时 它实际展布的范围. 风暴潮在从远海向近海侵漫过 程中, 海底对能量的削减产生了“破浪带”, 最大浪基 面深度似有升高的趋势. 即便如此, 黔中古陆北缘受 风暴影响的底栖组合仍限于BA3(水深一般不超过 60 $\mathrm{m})$ 而未深及 BA4 的最大深度 $(120 \mathrm{~m})$. 枝线贝类介壳 层指示的BA2 下部-BA3 上部可能系风暴浪能量开始 明显消减的深度. 相对于现代有些风暴浪能波及 200 $\mathrm{m}$ 的水深而言, 显然浅了许多, 这可能与风暴潮向岸 推进中, 被上扬子区广阔、坡度平缓的陆表海有效地 减弱了能量密切相关. 在黔北同一剖面上, 灰泥颗粒 岩(近源风暴产物)和颗粒灰泥岩(远源风暴产物)可以 纵向交替出现, 指示该时期风暴中心是来回摆动的, 而不是固定的, 这种摆动可能受控于海底地形和海 岸线的变化. 现代碎屑岩相的风暴沉积体系中, 在浪 基面附近所见的某些层理构造 ${ }^{[2]}$, 如丘状交错层理, 在本文研究实例中尚难识别.

Johnson ${ }^{[25]}$ 研究挪威南部兰多维列统Rytteraker组 Pentamerus 风暴层时, 通过贝壳年龄分布和风暴层/ 非风暴层堆积旋回分析, 推断其周期为 2 3 年. 这一 实例, 按Kidwell ${ }^{[26,27]}$ 风暴层分类, 属于“事件富集”层. 而黔北枝线贝类介壳层则属于 “复合或多次事件富 集” 层, 系多次风暴反复作用所致, 总体堆积时间可 能长达数万年. 枝线贝类为优势种的群落, 成分单调, 未经长距离搬运, 要达到 3 5 m厚的贝壳生长量, 没 有数万年的时间是不可能形成的.

对风暴周期的估计, 也值得探讨. 倘若风暴搅动 不频繁, 壳瓣应以原位生长方式与周围灰泥一起固 结成岩, 其后一般不大可能被全部再播扬起来, 最多 以岩石破碎成砾块后堆积, 可惜这种现象作者并未 在黔北相关地层中发现过. 由此推测, 风暴周期的上 限不比成岩固结的时间长, 风暴显然多发生于基底 
成岩固结之后, 这些枝线贝类群落已正常栖居一段 时期了. 由于介壳层中含有大量成年壳体, 即使个别 也非全部是风暴来临后的幸存者, 也需一定时间保 持正常生长状态和群落的再造, 推测风暴周期的下 限也不会低于这个范围. 受材料限制, 对枝线贝类壳 体生长年龄值统计和相关群落再造时间的研究, 目 前还无法进行. 严格说来, 这里所指的风暴周期应是 指地史尺度的频繁风暴期和无风暴期之间的时限, 而不是相当于现代大部分海区数次 \年风暴潮和无风 暴潮的周期.

埃隆期这片广阔海域的海底上，还栖息着其他 腕足动物群落, 它们也曾遭遇过风暴作用, 也可以构 成风暴介壳滩层. 如在黔北、川南石牛栏组上部灰黑 色介壳灰岩中, 笔者多次发现丰富、单一的五房贝属 (Pentamerus)或三分贝属(Trmerlla)介壳层; 在黔东北 香树园组中部灰质泥岩中, 则发现富产无洞贝类小 轭螺贝属 Zygospiraella 单一或优势种的介壳层. 此外, 黔北桐梓石牛栏组, 风暴可夭折幼小的叠层石. 尽管 它们与枝线贝类海底尸积群的分布范围不同(主要受 控于原始生态群落), 也遭到了风暴浪的侵袭. 然而, 对它们的研究已超出本文范围. 从某种程度上说, 枝 线贝类介壳层、其它腕足类层和叠层石能作为我们今 天解读远古风暴事件理想的载体, 得益于它们有较 坚固的壳体或特殊的生物个体建造方式. 若风暴浪 作用于那些“弱不禁风”的群落, 则很难将证据完全 保存下来, 也就更难被识别出来了.

\section{4 结论}

（ｉ）黔北下志留统白沙型浅海灰岩相内发育的 枝线贝类介壳层, 是近岸陆表海域发生风暴的重要 标志, 是相关群落经历大风暴导致巨浪搅动后的堆 积产物. 上扬子陆表海域尽管宽阔, 其南部边缘区还 是遭受了强烈的风暴作用. 划归 BA2-3 的枝线贝类 群落, 栖居水深约在 20 40 m 之间, 分布面积约为 $7500 \mathrm{~km}^{2}$, 说明风暴巨浪一直侵犯到这片海域, 并达 到这个海水深度.

(ii ) 枝线贝类介壳层主要形成动力乃是风暴和 海岸线形状共同导致的增水作用. 大量发育灰泥颗 粒岩可能指示近源风暴沉积, 未作长距离搬运; 而颗 粒灰泥岩沉积地点则远离风暴中心区，属于远源风 暴堆积. 介壳层厚度、灰泥颗粒岩和颗粒灰泥岩在纵 向上交替的沉积序列表明, 中兰多维列世, 上扬子海
域, 特别是黔中古陆以北的陆表海域, 曾多次遭受风 暴波及, 但风暴作用靶区中心是不断变化的.

(iii) 黔东北香树园组中发育珊瑚、层孔虫生物 礁, 推测当时的黔中古陆北缘, 其古地理位置很可能 在南半球靠近赤道浅海区, 是热带风暴而非寒带风具 风的波及区. 枝线贝类群落指示的生态位可能代表 了该时期海进的最大值 ${ }^{[7]}$, 随后的一次海退、伴随着 海底沉积物的重大变化, 导致枝线贝类群落退出本 区, 海底生态域发生了重要的性质变化.

致谢 陈旭、詹仁斌、王怿、张元动、樊隽轩, 贵州大学 王增琪和张振晗硕士研究生等在历次野外考察期间给予了 大力协助，两位匿名审稿人提出修改意见，作者特此一并 致谢.

\section{参考文献}

1 Ager D V. The Nature of Stratigraphic Record. New York: Wiley, 1973. $1-114$

2 Aigner T. Storm Depositional Systems. Lect Notes in Earth Sci, Vol 3. Berlin: Springer Verlag, 1985. 1-174

3 Barron E J. Severe storms during earth history. Geol Soc Amer Bull, 1989, 101: 601-612[DOI]

4 Baarli B G. Silurian cycles and proximality-trend analysis of tempestite deposits. In: Landing Ed, Johnson M E, eds. Silurian Cycles: Linkages of Dynamic Stratigraphy with Atmosphere, Oceanic and Tectonic Changes. New York State Mus Bull, 1998, 491: 75-88

5 戎嘉余, 张梓歆. 晚志留世五房贝类 Pentamerifera 属在中国的 首次发现. 古生物学报, 1988, 27(1): 13-20

6 张廷山, 兰光志, 高卫东, 等. 中国川西北地区志留纪生物礁. 成都: 成都科技大学出版社, 1994. 1-115

7 Rong J Y, Chen X, Su Y Z, et al. Silurian paleogeography of China. In: Landing Ed, Johnson M E, eds. Silurian Lands and Seas: Paleogeography Outside of Laurentia. New York State Mus Bull, 2003, 493: 243-298

8 葛治洲, 戎嘉余, 杨学长, 等. 西南地区碳酸盐生物地层. 见: 中国科学院南京地质古生物研究所, 著. 西南地区的志留系. 北 京: 科学出版社, 1979. 155-220

9 戎嘉余, 杨学长. 西南地区早志留世中晚期腕足动物群. 中国科 学院南京地质古生物研究所集刊, 1981, 13: 163-278

10 戎嘉余, 许汉奎, 杨学长. 志留纪腕足动物. 见: 中国科学院南 京地质古生物研究所, 编. 西南地区地层古生物手册. 北京: 科 学出版社, 1974. 195-208

11 李越. 华南晚奥陶世至早志留世生物礁的演化历程. 见: 戎嘉余, 方宗杰, 主编. 古生代生物灭绝事件和复苏一来自华南古生代 和三叠纪的证据. 合肥: 中国科技大学出版社, 2004. 187-222

12 葛治洲, 戎嘉余, 杨学长, 等. 西南地区志留系 10 条剖面资料. 见: 中国科学院南京地质古生物研究所, 编. 地层古生物, 1977, 92-111

13 Jin J S, Zhan R B, Rong J Y. Taxonomic reassessment of two vir- 
gianid brachiopod genera from the Upper Ordovician and Lower Silurian of South China. J Paleont, 2006, 80(1): 72-82[DOI]

14 Dunham R J. Classification of carbonate rocks according to depositional texture. Amer Assoc Petrol Geol Bull, 1962, 54: 108-121

15 Brenchley P J. Environmental changes close to the Ordovician-Silurian boundary. Geology, 1988, 43: 377-385

16 陈旭, 戎嘉余, 主编. 中国扬子区兰多维列统特列奇阶及其与英 国的对比. 北京: 科学出版社, 1996. 1-162

17 Loydell D K. Early Silurian sea-level changes. Geol Mag, 1998, 135: 447-471[DOI]

18 Copper P. Silurian and Devonian reefs: 80 million years of global greenhouse between two ice ages. In: Kiessling W, Flügel E, Golonka J, eds. Phanerozoic Reef Patterns. SEPM Spec Publ, 2002, 72: $181-238$

19 陈旭, 布科. 志留纪气候. 见: 陈旭, 阮亦萍, A J 布科, 主编. 中国古生代气候演变. 北京: 科学出版社, 2001. 35-39

20 Li Y, Kershaw S. Reef reconstruction after extinction event of Latest Ordovician in Yangtze Platform, South China. Facies, 2003, 48: $269-284$

21 贾振远, 李之琪, 编著. 碳酸盐岩沉积相和沉积环境. 武汉: 中
国地质大学出版社, 1989. 1-186

22 戎嘉余. 生态地层学的基础一一群落生态学研究. 见: 中国古生 物学会, 编. 中国古生物学会第十三、十四届学术年会论文选集. 合肥: 中国科学技术大学出版社, 1986. 1-24

23 Seilacher A. General remarks about event deposits. In: Einsele G, Seilacher A, eds. Cyclic and Event Stratification. New York: Springer-Verlag, 1982. 161-174

24 Jeffery D, Aigner T. Storm Sedimentation in the Carboniferous Limestones Near Weston-Super-Mare (Dinantian, SW-England). In: Einsele G, Seilacher A, eds. Cyclic and Event Stratification. New York: Springer-Verlag, 1982. 240—247

25 Johnson M E. Tempestites recorded as variable Pentamerus Layers in the Lower Silurian of southern Norway. J Paleont, 1989, 63(2): 195-205

26 Kidwell S M. Paleobiological and sedimentological implication of fossil concentrations. Nature, 1988, 318: 457-460[DOI]

27 Kidwell S M. Modles for fossil concentration: Paleobiolgical implications. Paleobiology, 1986, 12(1): 6-21 